\title{
SEM-EDS of Artifacts from the HMAV Bounty Discovered at Pitcairn Island
}

\author{
Abigail P Lindstrom ${ }^{1 *}$ and Nicholas WM Ritchie ${ }^{1}$ \\ 1. Materials Measurement Science Division, NIST, Gaithersburg, MD, USA. \\ * Corresponding author: abigail.lindstrom@nist.gov
}

In 1787, West India Merchantmen asked the English Government for an expedition to collect Bread Fruit and introduce it to West Indies. The Government assigned Sir Joseph Banks to organize it and Lieutenant William Bligh as Captain. The former Bethia [1], was purchased, renamed Bounty and refitted at Deptford including addition of copper sheathing and nails and a lead-lining for the former Captain's cabin for the breadfruit plants she would be acquiring. She was provisioned, manned, and set sail from Spithead on December 23, 1787. On April 28, 1788, after leaving Tahiti, First Mate Fletcher Christian and some of the crew mutinied taking the ship by force [2]. The ship, a few of the mutineers and some passengers from Tahiti arrived at Pitcairn Island in January 1790 where the Bounty was burned and scuttled some years later. [3]

In 1957, the National Geographic photographer Luis Marden discovered remains of the Bounty off Pitcairn Island and recovered sheathing, nails and other pieces [4]. A handful of samples were transferred to his friend, George Ellinger, a metallurgist at NIST. When he retired, the samples were transferred to Lance King who transferred them to the authors upon his retirement [5].

The samples consist of four pieces of metal, two pieces that are silvery covered in many layers of corrosion and contamination and two that are a darker red-brown covered in corrosion and contamination (see Figure 1.) Multiple regions of each sample were analyzed on a TESCAN MIRA-3 with 4 Pulsetor EDS detectors using NIST DTSA-II (free at https://www.cstl.nist.gov/div837/837.02/epq/dtsa2/index.html) [6] with SEMantics automation software [7]. Prior to analysis, the samples were carbon coated to mitigate surface charging. Quantitative compositional maps were generated.

The darker samples are likely a piece of copper sheathing and a sheathing nail. (Figure 2) The major element in the sheathing piece was copper, while the nail was copper with some tin. There were other elements present, such as sodium, chlorine, calcium, iron, and magnesium as well as carbon and oxygen likely from surface dirt. Our work is consistent with previous work by Viduka and Ness [3] who studied comparable material from the Bounty, but from a later 1998-1999 expedition using SEM-EDS (after cleaning and cutting) and ICP-MS after dissolution. The tin was added to help with corrosion resistance and hardness.

The silvery samples were mostly lead, possibly from the lining of the Captain's cabin for the plants (Figure 3). The larger piece had one end that was visibly cleaner and most analysis was done on the clean end, but one map was taken from the dirtier end and had higher levels of aluminum, silicon, magnesium and iron from contamination [8].

\section{References:}

[1] C Knight in “The Mariner's Mirror, Journal of the Society for Nautical Research”, Volume 22, Cambridge University Press, 1936, p. 182. 
[2] WHD Adams, "Famous Ships of the British Navy", Cassell, Petter and Galpin, London (1863) p. 97. [3] A Viduka and S Ness, Proceedings of Metal, National Museum of Australia, Canberra, (2004) p. 160.

[4] L Marden, National Geographic 111 (1957), p728.

[5] Lance King, personal communication, 2018.

[6] N Ritchie, Microscopy Today 19 (2011), p 26.

[7] N Ritchie and V Filip, Microsc. Microanal. 17(S2) (2011), p. 896.

[8] Certain products, either public domain or commercial, are identified in this paper. Identification of such products does not imply recommendation or endorsement by NIST, nor does it imply that the identified product is the best available.

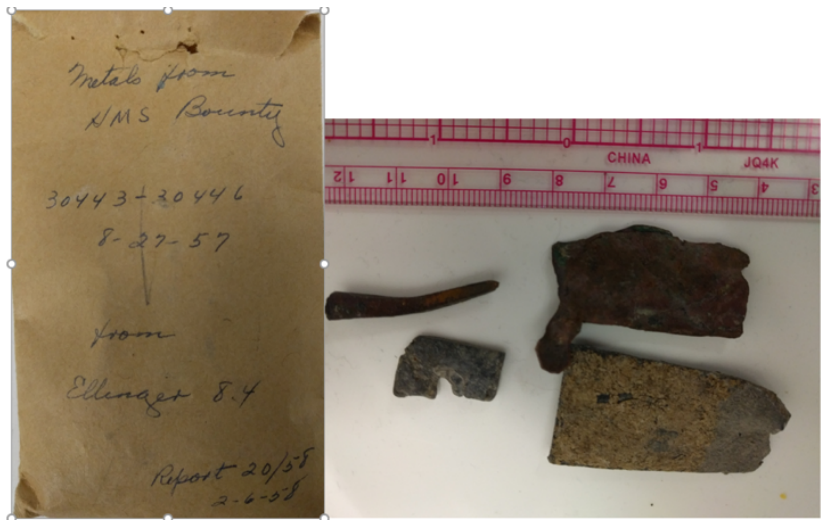

Figure 1. The envelope that the pieces were found in and the pieces themselves.
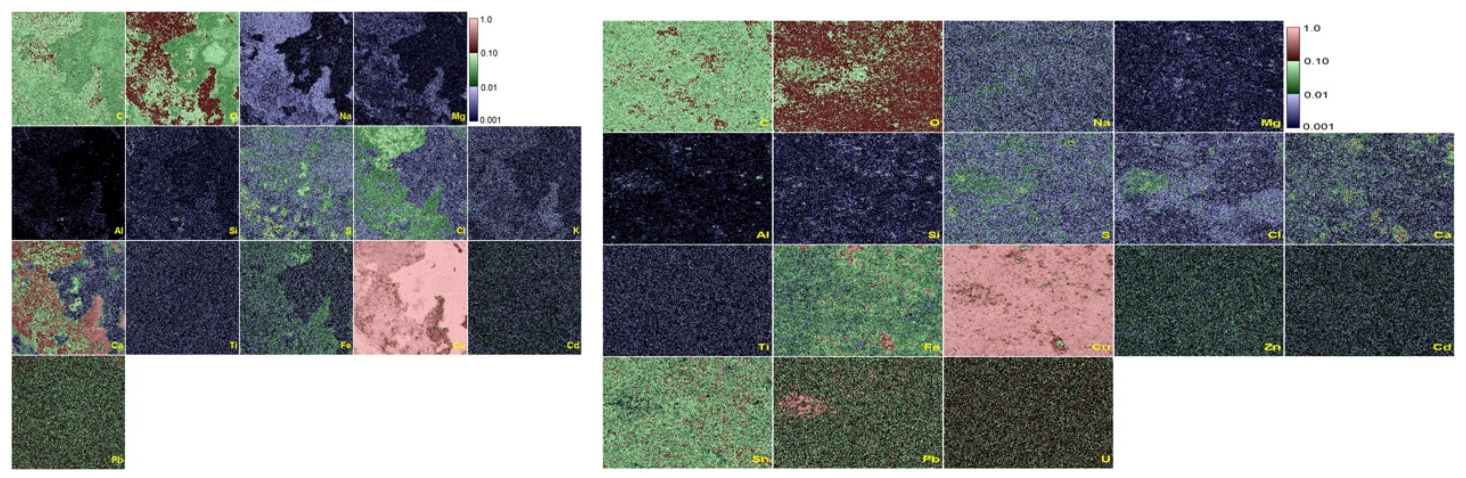

Figure 2. Maps of $1 \mathrm{~mm}^{2}$ areas of the surface of the large sheet (left) and the nail (right).
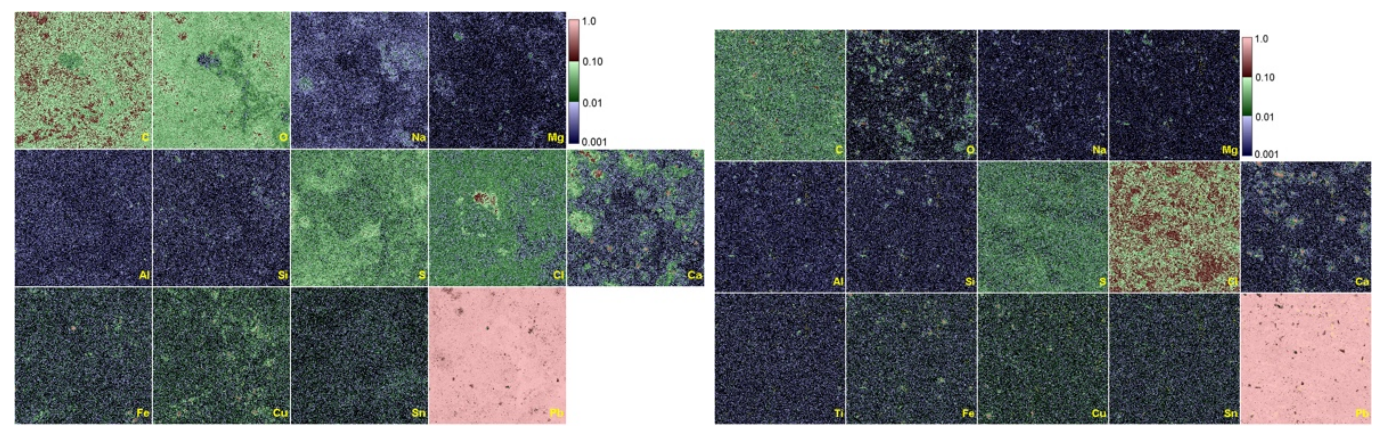

Figure 3. Maps of $1 \mathrm{~mm}^{2}$ areas of the surface of the large (left) and small (right) silvery pieces. 